\title{
Drug information update. Unconventional treatment strategies for schizophrenia: polypharmacy and heroic dosing
}

\author{
Bret A. Moore, ${ }^{1}$ Debbi A. Morrissette, ${ }^{2}$ Jonathan M. Meyer, ${ }^{3}$ Stephen M. Stahl ${ }^{2,4}$
}

BJPsych Bulletin (2017) 41, 164-168, doi: 10.1192/pb.bp.115.053223

\author{
'U.S. Army Regional Health Command- \\ Central, San Antonio, Texas, USA: \\ ${ }^{2}$ Neuroscience Education Institute, \\ Carlsbad, California, USA; ${ }^{3}$ California \\ Department of State Hospitals, \\ Sacramento, California, USA; \\ ${ }^{4}$ Department of Psychiatry, University \\ of Cambridge, Cambridge, UK \\ Correspondence to Stephen M. Stahl \\ (smstahl@neiglobal.com) \\ First received 26 Nov 2015, final \\ revision 6 Jul 2016, accepted 8 Jul \\ 2016 \\ (C) 2017 The Authors. This is an open- \\ access article published by the Royal \\ College of Psychiatrists and distributed \\ under the terms of the Creative \\ Commons Attribution License (http:// \\ creativecommons.org/licenses/by/ \\ 4.0), which permits unrestricted use, \\ distribution, and reproduction in any \\ medium, provided the original work \\ is properly cited. The view(s) \\ expressed herein are those of the \\ author(s) and do not reflect the official \\ policy or position of U.S. Army \\ Regional Health Command-Central, \\ the U.S. Army Medical Department, \\ the U.S. Army Office of the Surgeon \\ General, the Department of the Army \\ and Department of Defense or the U.S \\ Government.
}

Summary The majority of patients respond to antipsychotic monotherapy at standard doses, but a subset of patients will require more heroic measures that include antipsychotic polypharmacy and high-dose monotherapy. Indeed, research has shown that roughly $30 \%$ of patients with psychosis are prescribed multiple antipsychotic medications. We discuss the potential benefits and challenges of these approaches and provide a rationale for why and when they should be utilised.

Declaration of interest J.M.M. reports speaking or advising fees from Acadia Pharmaceuticals, Alkermes, Forum Pharmaceuticals, Merck, Otsuka America, Inc., Sunovion Pharmaceuticals and Teva Pharmaceutical Industries. S.M.S. has served as a consultant for Acadia, BioMarin, EnVivo Pharmaceuticals, Forum Pharmaceuticals, Jazz Pharmaceuticals, Orexigen Therapeutics, Otsuka, Pamlab, Servier, Shire, Sprout, Taisho Pharmaceutical, Takeda and Trius Therapeutics; as an Advisory Board Member for BioMarin, EnVivo, Forum, Genomind, Lundbeck, Otsuka, RCT Logic and Shire; on the Speakers Bureau for Forum, Takeda, Servier and Sunovion UK; and he has received research and/or grant support from Alkermes, Clintara, Eli Lilly, Forest Laboratories, Forum, Genomind, JayMac Pharmaceuticals, Jazz, Merck, Novartis, Otsuka, Pamlab, Pfizer, Servier, Shire, Sprout, Sunovion, Sunovion UK, Takeda, Teva and Tonix.
Schizophrenia is one of the most challenging psychiatric disorders faced by clinicians today, affecting roughly $1 \%$ of the population. ${ }^{1}$ Many out-patient clinics and virtually all in-patient facilities manage these often complex clinical cases. Since the introduction of the first-generation antipsychotics (FGA) and subsequent development of the dopamine hypothesis, blockade of dopamine $2\left(\mathrm{D}_{2}\right)$ receptors has been the primary goal of pharmacological intervention. Even with the development and proliferation of the secondgeneration antipsychotics (SGA), $\mathrm{D}_{2}$ blockade remains central to effective control of positive symptoms whereas serotonin $2 \mathrm{~A}\left(5-\mathrm{HT}_{2 \mathrm{~A}}\right)$ plays an important but secondary role in the modulation of dopamine, theoretically improving negative symptoms while reducing the risk of extrapyramidal symptoms. ${ }^{2}$

The term 'dopamine hypothesis' of schizophrenia is slowly being phased out, as more sophisticated imaging studies have identified the nature of the dopamine dysfunction and its locus within the striatum. The striatum is a major component of the basal ganglia, and is divided functionally into the dorsal sensorimotor portion, the central associative striatum, and the ventral limbic striatum. Recently it has been found that the best correlation between positive symptoms of psychosis in schizophrenia and levels of $\mathrm{D}_{2}$ activity is in the rostral caudate, a portion of the central associative striatum., We thus have in vivo confirmation of excessive $D_{2}$ neurotransmission and the relationship to the positive symptoms of schizophrenia. In the limbic striatum low dopamine release is directly related to the severity of negative symptoms; the lower the dopamine levels, the greater the negative symptom severity. ${ }^{3}$

While the goal of treatment is normalisation of $\mathrm{D}_{2}$ neurotransmission in the striatum, a subset of patients do not respond to traditional treatment algorithms which include antipsychotic monotherapy at dosing levels defined 
in registrational trials. Consequently, many patients continue to exhibit uncontrolled positive and negative symptoms as well as manifesting aggressive and impulsive behaviours. ${ }^{5}$ It has been argued that 'unconventional' strategies for better management of treatment-resistant psychosis should be employed. ${ }^{6-8}$ The two primary methods we discuss in the following pages include antipsychotic polypharmacy and high-dose monotherapy.

\section{Why do standard treatments sometimes fail?}

To effectively treat the positive symptoms of schizophrenia it is important to achieve at least $60 \%$ striatal $\mathrm{D}_{2}$ blockade with antipsychotics. ${ }^{9}$ The exception is clozapine, which has been shown to have some antipsychotic effect at as little as $20 \%$ blockade. $^{10}$ Beyond $80 \% \quad \mathrm{D}_{2}$ occupancy, risk of extrapyramidal side-effects (EPS) increases, leading to non-adherence and treatment failure. Therefore, the 'sweet spot' of $\mathrm{D}_{2}$ receptor blockade for most patients is between 60 and $80 \%{ }^{6}$ However, in some treatmentresistant cases, particularly when aggression and impulsivity are of concern, moving beyond $80 \%$ may be necessary. ${ }^{6,8,11-14}$ Moreover, there is significant evidence from the literature that a substantial portion of patients tolerate plasma antipsychotic levels consistent with $>80 \%$ $\mathrm{D}_{2}$ occupancy.

One of the early imaging studies from 1997 noted that a large fraction of patients stabilised on low-dose oral haloperidol had plasma levels associated with $>80 \% \mathrm{D}_{2}$ occupancy; ${ }^{12}$ however, prior clinical studies found that even at a plasma haloperidol level of $6 \mathrm{ng} / \mathrm{ml}$ (predicted $90 \% \mathrm{D}_{2}$ occupancy), only $30 \%$ experienced adverse effects. ${ }^{13}$ A similar pattern is seen with risperidone. The pivotal trials studied doses of $10 \mathrm{mg}$ and $16 \mathrm{mg}$, which correlate with a plasma active moiety level of $70 \mathrm{ng} / \mathrm{ml}$ and $112 \mathrm{ng} / \mathrm{ml}$, respectively. ${ }^{15}$ The plasma level of $70 \mathrm{ng} / \mathrm{ml}$ would correspond to a $\mathrm{D}_{2}$ occupancy of $85 \% ;{ }^{14}$ however, despite this high level of predicted $\mathrm{D}_{2}$ occupancy, the proportion of patients on $10 \mathrm{mg}$ who required anti-Parkinsonian treatment was only $31 \%$. $^{16}$

\section{Pharmacokinetic failure}

Pharmacokinetics is the umbrella term that covers drug absorption, bioavailability, distribution, metabolism and excretion. The role of pharmacokinetics in antipsychotic treatment failure is relatively simple. Through abnormal pharmacokinetic processes such as poor absorption, rapid metabolism and enzymatic polymorphisms, antipsychotic plasma levels do not reach the threshold associated with $60 \%$ striatal $\mathrm{D}_{2}$ occupancy. This leads to continued psychotic symptoms. It also leads to frustration and confusion for clinicians in that the patient does not sufficiently respond to standard treatment algorithms.

\section{Pharmacodynamic failure}

Pharmacodynamics encompasses receptor binding and sensitivity, postreceptor effects, and chemical communication. Pharmacodynamic treatment failure with regard to antipsychotics is the inability to provide significant amelioration of psychotic symptoms in spite of achieving plasma levels associated with at least $60-80 \% \mathrm{D}_{2}$ occupancy. ${ }^{17}$ Although adequate drug plasma levels are achieved, patients with treatment-resistant psychosis present with continued positive, cognitive and aggressive symptoms. The treatment failure associated with pharmacodynamic influences is hypothesised to be related to lack of $\mathrm{D}_{2}$ receptor sensitivity or hypersensitivity. When patients manifest a lack of extrapyramidal adverse effects or akathisia, increasing drug doses to achieve plasma levels that are associated with $>80 \% \quad \mathrm{D}_{2}$ blockade may be necessary to provide symptom control. ${ }^{18-20}$ The overriding principle is that there are a subset of patients who both tolerate and require high levels of $D_{2}$ antagonism for symptomatic relief.

\section{The importance of being patient}

While recent studies have demonstrated that minimal response after 2 weeks on a particular antipsychotic dose portends a low likelihood of week 6 response on that dose, the full therapeutic effects of adequate $\mathrm{D}_{2}$ receptor blockade in schizophrenia may not be apparent until many weeks or months later. ${ }^{7}$ Therefore, patience in pharmacological treatment of psychosis is critical when a patient exhibits partial response. ${ }^{7,11}$ For example, Robinson and colleagues found that in a sample of 118 first-episode patients with schizophrenia or schizoaffective disorder only $20 \%$ responded to treatment at 4 weeks. The picture was quite different at 52 weeks; roughly $87 \%$ responded to treatment. ${ }^{21}$ Other studies of ziprasidone, risperidone and olanzapine have shown continued improvement over several months of treatment. ${ }^{11}$

\section{Strategies to use prior to heroic measures}

We believe polypharmacy and high dosing should not be the initial approach to treating schizophrenia. However, considering that roughly $30 \%$ of patients with psychosis are on multiple antipsychotics, the practice is far from rare. ${ }^{22,23}$ In an effort to address the growing practice of antipsychotic polypharmacy and high dosing of antipsychotics in spite of little support in the literature, Stahl provides 12 case-based recommendations. ${ }^{7}$ We review several below.

\section{Utilise monotherapy first to include clozapine}

Sequential trials of at least two SGAs are recommended. If both trials fail, consideration of an FGA is appropriate. Also, it is important to not overlook clozapine as monotherapy. The efficacy of clozapine in treatment-resistant schizophrenia, particularly with regard to aggression and violence, is well documented. ${ }^{24-26}$ However, some clinicians may be hesitant to initiate a trial of clozapine owing to fear of side-effects such as agranulocytosis.

\section{Monitor blood levels}

Securing drug plasma levels is the only way to know whether treatment failure is due to a pharmacokinetic issue such as rapid metabolism or a cytochrome $\mathrm{P} 450$ polymorphism, or simply poor adherence with oral therapy. 
Likewise, blood levels can alert you to pharmacodynamic abnormalities which occur when treatment response does not correlate with adequate dosing. Blood level monitoring of both FGAs and SGAs can provide the clinician with important information which can guide the treatment plan for patients with treatment-resistant psychosis. This is supported by the recent work of Lopez \& Kane as relevant to haloperidol, fluphenazine, perphenazine, risperidone, olanzapine and clozapine. ${ }^{27}$

\section{Time may not be on your side}

As noted above, it takes some patients longer than others to respond to antipsychotic treatments. Granted, it may not be possible to wait several weeks (and certainly not months) in acute settings or when a patient's behaviour is potentially harmful to self or others, but when possible, allowing adequate time for full response may be all that is needed when a patient has exhibited a partial response. The result of impatience is that a second antipsychotic may be prescribed or a single medication may be dosed in an unnecessarily aggressive manner.

\section{Double-check the diagnosis}

It is common practice to rethink the primary diagnosis if the treatment plan appears ineffective. Once pharmacokinetic, pharmacodynamic or time-course failures have been ruled out, the presence of substance misuse or a personality disorder or neurological illness should be considered.

\section{Antipsychotic polypharmacy}

Although a number of published treatment guidelines for schizophrenia are available, some of which conflict with each other, it is clear that clinicians should utilise a monotherapy approach to antipsychotic medication use. ${ }^{28}$ Multiple trials of antipsychotic medications, generally SGAs to include clozapine, are recommended. In fact, divergence from this sequential clinical progression has historically been met with scepticism, caution and outright criticism. ${ }^{29-36}$ It is certainly understandable why this is the case. The literature is replete with evidence supporting the efficacy of monotherapy for schizophrenia. Furthermore, the pitfalls associated with combining antipsychotics are well documented. Increased side-effects, higher medication costs, scant information supporting efficacy, and suboptimal outcomes are all problematic with regard to antipsychotic polypharmacy. ${ }^{29-36}$ So, why the need to even review the topic? The reality is that patients included in research studies are generally those who are able to give consent, exhibit less violence and less impulsivity, have lower rates of chemical dependency, and are less likely to have histories of sequential trials of antipsychotics at documented therapeutic levels. ${ }^{7,8}$ In other words, consistent with much of psychiatry research, they are healthier and not mirror images of the patients seen in clinical practice. Therefore, we believe a strict adherence to a treatment guideline based on highly selective samples does not necessarily translate well to community-based out-patient clinics and in-patient facilities.
We acknowledge that antipsychotic monotherapy is sufficient for the majority of patients with schizophrenia and that adherence to established guidelines should generally occur. Indeed, recent studies support this position. A 2004 study by Suzuki and colleagues revealed that when patients with schizophrenia were switched from multiple antipsychotics to monotherapy, roughly half maintained gains whereas a quarter showed improvements. Another quarter of the sample decompensated. ${ }^{37}$ In a similar study by Essock and colleagues it was found that patients switched to monotherapy maintained gains, but also showed improvement in metabolic effects assumed to be caused by antipsychotic polypharmacy. It should be noted that approximately a third of patients required multiple antipsychotics. ${ }^{23}$ However, some evidence supports the use of antipsychotic polypharmacy. A recent meta-analysis of randomised controlled trials comparing antipsychotic monotherapy and polypharmacy highlighted that polypharmacy may be superior to monotherapy in certain clinical cases. ${ }^{38}$

In addition to achieving adequate $\mathrm{D}_{2}$ occupancy, antipsychotic polypharmacy also exploits other receptorbinding properties that could lead to improvement in other schizophrenia symptom clusters. For example, serotonergic, noradrenergic and histaminergic binding theoretically ameliorate depression, anxiety, insomnia, impulsivity and aggression. On the flip side, however, the patient is potentially exposed to adverse side-effects from multiple receptor binding or excessive binding via similar properties shared by antipsychotics (e.g. excessive histaminergic binding leading to daytime sedation or appetite stimulation and weight gain). Consequently, combining antipsychotics should be done rationally based on their binding profiles. One clear example is the need to avoid combining the partial $\mathrm{D}_{2}$ agonism of aripiprazole with antipsychotics with full $\mathrm{D}_{2}$ antagonism. The binding interference may lead to a worsening of symptoms due to aripiprazole's high affinity for the $\mathrm{D}_{2}$ receptor, and the fact that even low doses such as $10 \mathrm{mg}$ achieve $83 \% \mathrm{D}_{2}$ occupancy, and thus may displace full antagonists. $^{6}$

\section{High dosing of antipsychotics}

Antipsychotic polypharmacy is not the only means of addressing the more complex and treatment-resistant cases of schizophrenia. High-dose monotherapy is a viable option as well. In fact, it has been argued that if the goal is to occupy a greater degree of $\mathrm{D}_{2}$ receptors in order to address treatment-resistant positive and aggressive symptoms, high-dose monotherapy is the preferred option when compared with polypharmacy. High-dose monotherapy does, however, come at a greater financial expense and the risk of increased metabolic and other potential treatment-limiting side-effects. ${ }^{11}$

It is impossible to know what dose of a particular antipsychotic is required to achieve the intended outcome. Therefore, the prudent action is to start low within the US Food and Drug Administration (FDA)- and British National Formulary (BNF)-approved guidelines for the particular medication. The medication can be gradually increased outside the FDA-approved dosing window until therapeutic 
response occurs or the patient develops intolerable sideeffects. It is important that informed consent is obtained and treatment rationale is well documented when this occurs. Below we discuss the typical dosing ranges and special considerations for high dosing of the antipsychotics. A more detailed analysis can be found in Stahl \& Morrissette's review of the topic. ${ }^{11}$

\section{Clozapine}

Clozapine is typically only recommended after subsequent trials of other antipsychotics have failed. This is primarily owing to its side-effect profile. At typical dosing of 300$450 \mathrm{mg} /$ day, clozapine binds to less than $50 \%$ of $\mathrm{D}_{2}$ receptors, but as noted earlier, the antipsychotic benefits with this medication can be seen at as low as $20 \%$ occupancy. ${ }^{10}$ A meta-analysis by Davis \& Chen revealed that patients on high levels of clozapine responded more frequently than those on low levels. ${ }^{39}$ Clozapine can be dosed as high as $900 \mathrm{mg} /$ day, but seizure risk does increase with higher plasma levels, so titration to this dose should be done slowly. Furthermore, due to the diverse binding profile of clozapine, improvement in multiple symptoms clusters is possible.

\section{Quetiapine}

Quetiapine has a relatively weak affinity for $D_{2}$ receptors and often requires high dosing to achieve intended outcomes. Only at the upper range of $400-800 \mathrm{mg} /$ day are the antipsychotic properties of the medication seen. It is generally believed that a dose of $1200 \mathrm{mg}$ /day is no more effective than the typical dosing range and carries greater incidence of metabolic effects; however, clinical practice has shown that $1800 \mathrm{mg} /$ day may be useful in treating violent patients. $^{2,5,39}$

\section{Olanzapine}

Doses of olanzapine between 10 and $20 \mathrm{mg} /$ day equate to $60-80 \% \mathrm{D}_{2}$ occupancy. Higher doses of $40-60 \mathrm{mg}$ daily appear to be more effective, particularly with aggressive patients and in some forensic settings. ${ }^{2,32,40,41}$ A note of caution is that as plasma levels increase the risks of anticholinergic and metabolic effects also increase., ${ }^{5,10}$

\section{Risperidone/paliperidone}

Risperidone reaches $70-80 \%$ of $\mathrm{D}_{2}$ occupancy at doses between 2 and $6 \mathrm{mg} /$ day. The risk of EPS is positively correlated with dose. Doses above $8 \mathrm{mg} /$ day are generally not considered beneficial for most patients, but in some, the side-effects may not appear until higher dosages. ${ }^{5}$ As noted previously, even at $10 \mathrm{mg} /$ day only $31 \%$ of patients required anti-Parkinsonian medication in the pivotal trials, again providing evidence that a subgroup may both require and tolerate higher dosages and plasma levels. ${ }^{16}$ Risperidone's active metabolite paliperidone has less chance of drug-drug interactions as it is not metabolised by the liver. Similar to risperidone, paliperidone carries increased risk of EPS as the dose increases. ${ }^{11}$

\section{Ziprasidone}

Data support the use of high doses of ziprasidone, particularly in forensic settings at $360 \mathrm{mg} /$ day. $^{2-5,40,41}$ It can be difficult to achieve adequate plasma levels with ziprasidone in out-patient settings as food is required to increase absorption. It has been reported that ziprasidone has historically been under-dosed due to concern about increased agitation and QTc prolongation.

\section{Aripiprazole}

Aripiprazole has a different mechanism of action compared with the 'first wave' of SGAs. Contrary to its predecessors, high doses of aripiprazole may not result in increased efficacy in schizophrenia. This is due to its partial agonist properties and high affinity for $\mathrm{D}_{2}$ receptors. ${ }^{11}$ Doses of $40 \mathrm{mg}$ /day are associated with $96.8 \% \mathrm{D}_{2}$ occupancy, so further increases will not have an impact on $\mathrm{D}_{2}$ neurotransmission to any considerable extent.

\section{Asenapine, iloperidone, and lurasidone}

Asenapine, iloperidone, and lurasidone are newer atypical antipsychotics. Consequently, there is limited information that supports their use in high doses. Although doses of asenapine of $30-40 \mathrm{mg} /$ day may be effective for some treatment-resistant cases, there are virtually no data supporting use at these higher doses, and the buccal absorption of asenapine declines significantly for each $5 \mathrm{mg}$ increase in the dose. As with asenapine, there are limited to no data supporting the use of iloperidone at high doses. One treatment-limiting issue with iloperidone is orthostatic hypotension. Lurasidone is approved up to $160 \mathrm{mg} /$ day for schizophrenia, but higher dosages have not been studied for efficacy, only for safety (e.g. thorough QT studies up to $600 \mathrm{mg}$ ). Similar to ziprasidone, lurasidone should be taken with food to increase absorption. ${ }^{11}$

\section{Summary}

Schizophrenia is a relatively common psychiatric disorder but it is often difficult to treat. Although antipsychotic monotherapy at standard dosing levels is sufficient for the majority of patients, a subset will require 'unconventional' approaches such as antipsychotic polypharmacy and higher than normal dosing. If done cautiously and rationally, these approaches can provide much-needed benefit for those most in need of relief.

\section{About the authors}

Bret A. Moore, Warrior Resiliency Program, U.S. Army Regional Health Command-Central, San Antonio, and University of Texas Health Science Center at San Antonio, San Antonio, Texas, USA; Debbi A. Morrissette, Neuroscience Education Institute, Carlsbad, California, and Department of Biology, Palomar College, San Marcos, California, USA; Jonathan M. Meyer, California Department of State Hospitals, Sacramento, California, and Department of Psychiatry, University of California, San Diego, USA; Stephen M. Stahl, Neuroscience Education Institute, Carlsbad, California, Department of Psychiatry, University of California, San Diego, California, USA, and Department of Psychiatry, University of Cambridge, Cambridge, UK. 


\section{References}

1 Perälä J, Suvisaari J, Saarni SI, Kuoppasalmi K, Isometsä E, Pirkola S, et al. Lifetime prevalence of psychotic and bipolar I disorders in a general population. Arch Gen Psychiatry 2007; 64: 19-28.

2 Schwartz T, Stahl S. Treatment strategies for dosing the second generation antipsychotics. CNS Neurosci Ther 2011; 17: 110-7.

3 Kegels LS, Abi-Dargham A, Frankle WG, Gil R, Cooper TB, Slifstein M, et al. Increased synaptic dopamine function in associative regions of the striatum in schizophrenia. Arch Gen Psych 2010; 67: 231-9.

4 Thompson JL, Urban N, Slifstein M, Xu X, Kegeles LS, Girgis RR, et al. Striatal dopamine release in schizophrenia comorbid with substance dependence. Mol Psychiatry 2013; 18: 909-15.

5 Stahl SM. Stahl's Essential Psychopharmacology: Neuroscientific Basis and Practical Applications, 4th edn. Cambridge University Press, 2013.

6 Morrissette DA, Stahl SM. Treating the violent patient with psychosis or impulsivity utilizing antipsychotic polypharmacy and high-dose monotherapy. CNS Spectr 2014; 19: 439-48.

7 Stahl SM. Emerging guidelines for the use of antipsychotic polypharmacy. Rev Psiquiatr Salud Ment 2013; 6: 97-100.

8 Stahl SM. Antipsychotic polypharmacy: never say never, but never say always. Acta Psychiatr Scand 2012; 125: 349-51.

9 Uchida H, Takeuchi H, Graff-Guerrero A, Suzuki T, Watanabe K, Mamo DC. Dopamine $D_{2}$ receptor occupancy and clinical effects: a systematic review and pooled analysis. J Clin Psychopharmacol 2011; 31: 497-502.

10 Uchida H, Takeuchi H, Graff-Guerrero A, Suzuki T, Watanabe K, Mamo DC. Predicting dopamine D receptor occupancy from plasma levels of antipsychotic drugs: a systematic review and pooled analysis. J Clin Psychopharmacol 2011; 31: 318-25.

11 Stahl S, Morrissette D. Should high dose or very long-term antipsychotic monotherapy be considered before antipsychotic polypharmacy? In Polypharmacy in Psychiatry Practice. Vol. I: Multiple Medication Use Strategies (ed MS Ritsner): pp. 107-125. Springer Netherlands, 2013.

12 Kapur S, Zipursky R, Roy P, Jones C, Remington G, Reed K, et al. The relationship between $D_{2}$ receptor occupancy and plasma levels on low dose oral haloperidol: a PET study. Psychopharmacology 1997; 131: $148-52$.

13 Midha KK, Hubbard JW, Marder SR, Marshall BD, Van Putten T. Impact of clinical pharmacokinetics on neuroleptic therapy in patients with schizophrenia. J Psychiatry Neurosci 1994; 19: 254-64.

14 Remington G, Mamo D, Labelle A, Reiss J, Shammi C, Mannaert E, et al. A PET study evaluating dopamine $D_{2}$ receptor occupancy for longacting injectable risperidone. Am J Psychiatry 2006; 163: 396-401.

15 de Leon J, Sandson NB, Cozza KL. A preliminary attempt to personalize risperidone dosing using drug-drug interactions and genetics, Part II. Psychosomatics 2008; 48: 347-61.

16 Marder SR, Meibach RC. Risperidone in the treatment of schizophrenia. Am J Psychiatry 1994; 151: 825-35.

17 Correll CU. From receptor pharmacology to improved outcomes: individualising the selection, dosing, and switching of antipsychotics. Eur Psychiatry 2010; 25: S12-21.

18 Remington G, Kapur S. Antipsychotic dosing: how much but also how often? Schizophr Bull 2010; 36: 900-3.

19 Samaha AN, Seeman P, Stewart J, Rajabi H, Kapur S. 'Breakthrough' dopamine supersensitivity during ongoing antipsychotic treatment leads to treatment failure over time. J Neurosci 2007; 27: 2979-86.

20 Seeman P. Dopamine $D_{2}$ receptors as treatment targets in schizophrenia. Clin Schizophr Relat Psychoses 2010; 4: 56-73.
21 Robinson DG, Woerner MG, Alvir JM, Geisler S, Koreen A, Sheitman B, et al. Predictors of treatment response from a first episode of schizophrenia or schizoaffective disorder. Am J Psychiatry 1999; 156: 544-9.

22 Längle G, Steinert T, Weiser P, Schepp W, Jaeger S, Pfiffner C, et al. Effects of polypharmacy on outcome in patients with schizophrenia in routine psychiatric treatment. Acta Psychiatr Scand 2012; 125: 372-81.

23 Essock SM, Schooler NR, Stroup TS, McEvoy JP, Rojas I, Jackson C, et al. Effectiveness of switching from antipsychotic polypharmacy to monotherapy. Am J Psychiatry 2011; 168: 702-8.

24 Volavka J, Citrome L. Heterogeneity of violence in schizophrenia and implications for long-term treatment. Int J Clin Pract 2008; 62: 1237-45.

25 Volavka J, Czobor P, Nolan K, Sheitman B, Lindenmayer JP, Citrome L, et al. Overt aggression and psychotic symptoms in patients with schizophrenia treated with clozapine, olanzapine, risperidone, or haloperidol. J Clin Psychopharmacol 2004; 24: 225-8.

26 Volavka J, Citrome L. Pathways to aggression in schizophrenia affect results of treatment. Schizophr Bull 2011; 37: 921-9.

27 Lopez L, Kane J. Recommendations for the monitoring of serum concentrations of antipsychotic drugs in the treatment of schizophrenia. J Clin Psychiatry 2015; 76: 1249-50.

28 Stahl SM, Morrissette DA, Citrome L, Saklad SR, Cummings MA Meyer JM, et al. 'Meta-guidelines' for the management of patients with schizophrenia. CNS Spectr 2013; 18: 150-62.

29 Stahl SM. Antipsychotic polypharmacy, part I: therapeutic option or dirty little secret? J Clin Psychiatry 1999; 60: 425-6.

30 Stahl SM. Antipsychotic polypharmacy, part II: tips on use and misuse. J Clin Psychiatry 1999; 60: 506-7.

31 Stahl SM. Antipsychotic polypharmacy: squandering precious resources? J Clin Psychiatry 2002; 63: 93-4.

32 Stahl SM, Grady MM. A critical review of atypical antipsychotic utilization: comparing monotherapy with polypharmacy and augmentation. Cur Med Chem 2004; 11: 313-26.

33 Stahl SM. Focus: antipsychotic polypharmacy - evidence based prescribing or prescribing based evidence? Int J Neuropsychopharmacol 2004; 7: 113-6.

34 Stahl SM, Grady M. High cost use of second-generation antipsychotics under California's Medicaid program. Psychiatr Serv 2004; 57: 127-9.

35 Stahl SM. Antipsychotic polypharmacy: evidence based or eminence based? Acta Psychiatr Scand 2002; 106: 321-2.

36 Stahl SM, Freudenreich O, Goff D. A successful antipsychotic combination trial. Quo Vadis? Acta Psychiatr Scand 2004; 110: 241-2.

37 Suzuki T, Uchida H, Tanaka KF, Nomura K, Takano H, Tanabe A, et al. Revising polypharmacy to a single antipsychotic regimen for patients with chronic schizophrenia. Int J Neuropsychopharmacol 2004; 7: 133-42.

38 Correll CU, Rummel-Kluge C, Corves C, Kane JM, Leucht S Antipsychotic combinations vs monotherapy in schizophrenia: a meta-analysis of randomized controlled trials. Schizophr Bull 2009; 35 443-57.

39 Davis JM, Chen N. Dose response and dose equivalence of antipsychotics. J Clin Psychopharmacol 2004; 24: 192-208.

40 Mauri MC, Volonteri LS, Colasanti A, Fiorentini A, De Gaspari IF, Baregg SR. Clinical pharmacokinetics of atypical antipsychotics: a critical review of the relationship between plasma concentrations and clinical response. Clin Pharmacokinet 2007; 46: 359-88.

41 Barnes TR, Paton C. Antipsychotic polypharmacy in schizophrenia: benefits and risks. CNS Drugs 2011; 25: 383-99. 